\title{
Container Mosquito Habitat Community Cleanup: A How-To Guide for Event Organization'
}

\author{
Amy Hallock, Eva A. Buckner, Ricky W. Telg, and Alena R. Poulin²
}

\section{Introduction}

Summer in Florida means rain and time spent outdoors. This can be a perfect recipe for an encounter with invasive container mosquitoes like the yellow fever mosquito, Aedes aegypti, (Figure 1) and the Asian tiger mosquito, Aedes albopictus (Figure 2). Adult female container mosquitoes lay their eggs in small water-filled containers. The mosquitoes that hatch spend their immature life stages, larvae and pupae, in these containers (Figure 3).

Immature container mosquito habitats can be natural or artificial. Examples of natural container habitats include tree and rock holes, bamboo plants, and bromeliads. Rainwater storage barrels, bird baths, as well as discarded or abandoned items like tires, jars, cans, and buckets are examples of artificial container habitats (Figures $4-5$ ). Any discarded item that holds water can become a habitat for immature mosquitoes (Yee 2008). Even something as small as a water bottle cap will produce mosquitoes.

The yellow fever mosquito and the Asian tiger mosquito are the primary vectors of multiple mosquito-borne viruses

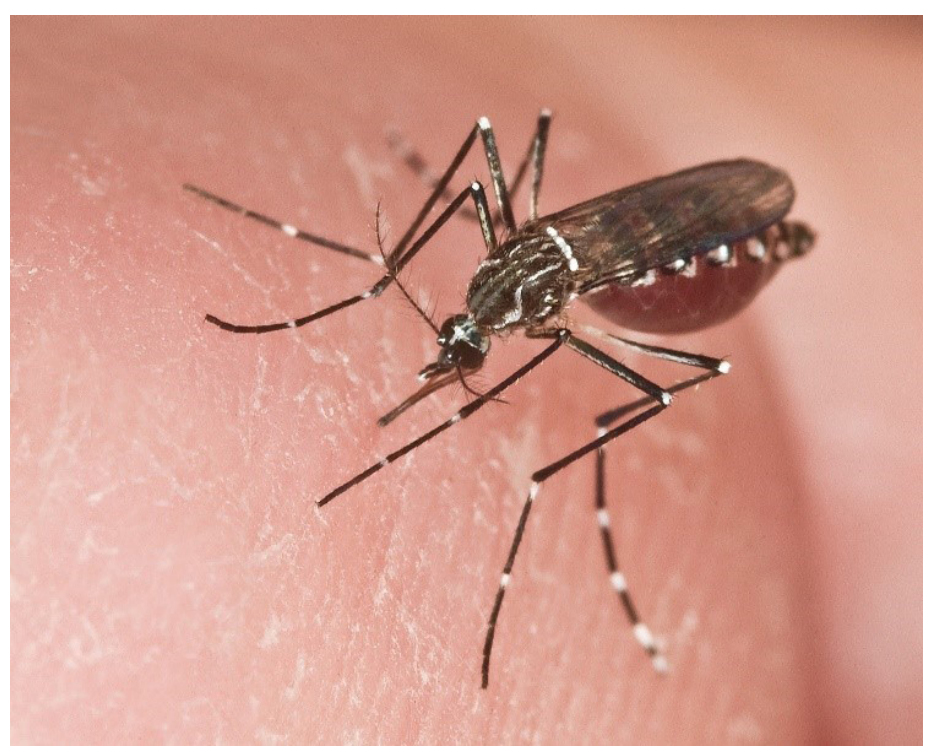

Figure 1. Adult female yellow fever mosquito, Aedes aegypti. Credit: James Newman, UF/IFAS

including dengue, chikungunya, and Zika that can cause illness in humans (Radke et al. 2012, Bortel et al. 2014, Campos et al. 2015). In certain areas of the world where the yellow fever mosquito, Asian tiger mosquito, and one or

1. This document is ENY-2047, one of a series of the Entomology and Nematology Department, UF/IFAS Extension. Original publication date August 2020. Visit the EDIS website at https://edis.ifas.ufl.edu for the currently supported version of this publication.

2. Amy Hallock, University of South Florida; Eva A. Buckner, Florida Medical Entomology Laboratory (FMEL) Research and Education Center; Ricky W. Telg, professor; Department of Agricultural Education and Communication; and Alena R. Poulin,media specialist I, B.S.,Center for Public Issues Education in Agriculture and Natural Resources; UF/IFAS Extension, Gainesville, FL 32611.

Prevent \& Protect: Mosquito Control Messages for Your Community is supported by the Smith-Lever Special Needs Competitive Grant Program [grant award no. 2016-41210-25622] from the USDA National Institute of Food and Agriculture. Any opinions, findings, conclusions, or recommendations expressed in this work are those of the author(s) and do not necessarily reflect the view of the U.S. Department of Agriculture. This work is also supported by a grant from the Florida Department of Health. Special thanks to the following organizations for their assistance in developing the content for this project: Florida Department of Agriculture and Consumer Services, Centers for Disease Control and Prevention (CDC) Southeastern Center of Excellence in Vector Borne Diseases, and UF/IFAS Department of Entomology and Nematology.

The Institute of Food and Agricultural Sciences (IFAS) is an Equal Opportunity Institution authorized to provide research, educational information and other services

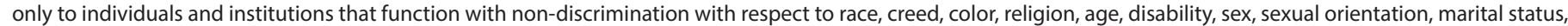

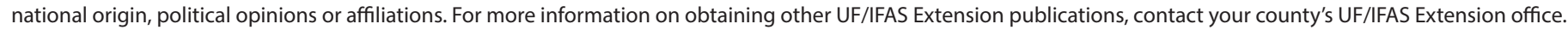
U.S. Department of Agriculture, UF/IFAS Extension Service, University of Florida, IFAS, Florida A \& M University Cooperative Extension Program, and Boards of County Commissioners Cooperating. Nick T. Place, dean for UF/IFAS Extension. 


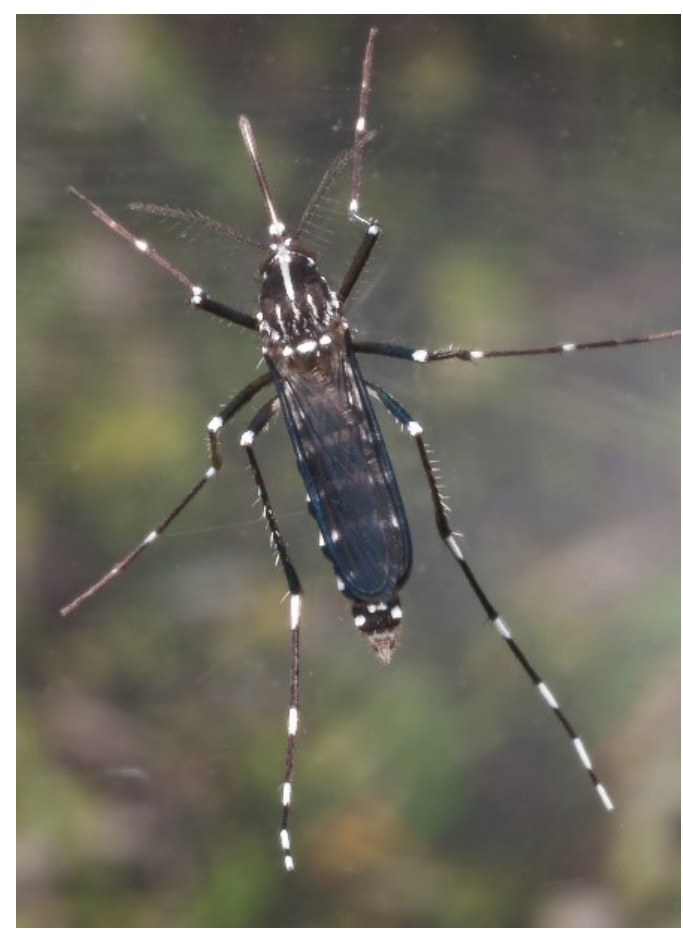

Figure 2. Adult female Asian tiger mosquito, Aedes albopictus. Credit: James Newman, UF/IFAS

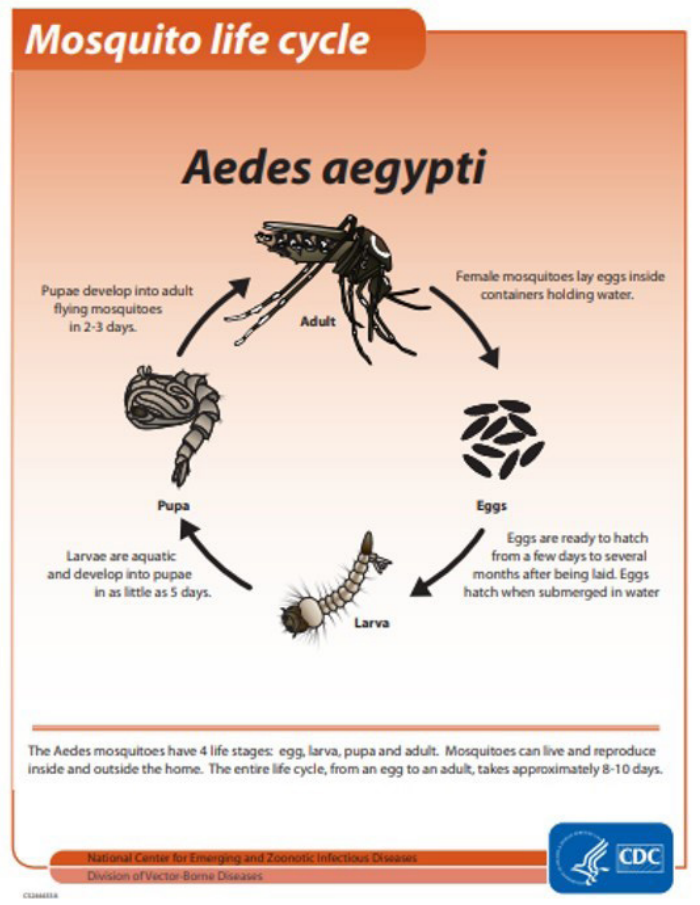

Figure 3. Life cycle for container mosquitoes like Aedes aegypti. Credit: Centers for Disease Control (CDC).

more of the viruses they transmit are established, they pose a significant threat to public health. In areas like Florida where the yellow fever mosquito and Asian tiger mosquito are established but the viruses they transmit are not, these two container mosquitoes still present public health concerns (Parker et al. 2019). If environmental conditions are favorable for transmission, virus introductions can lead to sporadic human disease outbreaks and cases. For

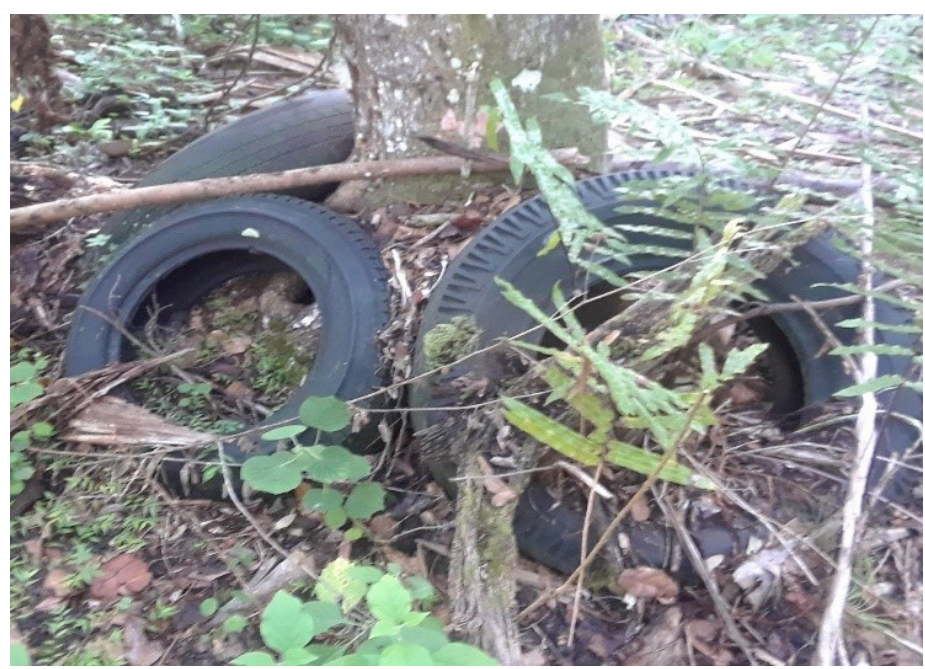

Figure 4. Discarded tires, which are a popular habitat of immature container mosquitoes.

Credit: Amy Hallock, UF/IFAS

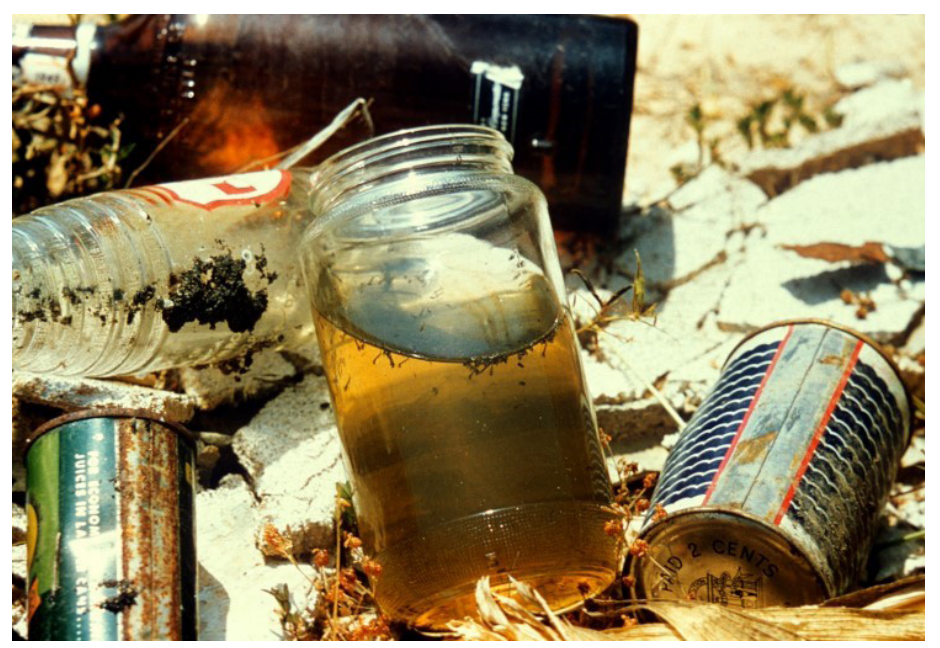

Figure 5. Immature mosquitoes in a discarded water-filled jar that is surrounded by other potential container mosquito habitats.

Credit: Graham Heid and Dr. Harry D. Pratt, CDC Public Health Image Library.

example, virus introductions in Florida within the past 15 years resulted in dengue, chikungunya, and Zika outbreaks with 111, 11, and 300 human cases, respectively (Radke et al. 2012, Kendrick et al. 2014, Rey 2014, Arévalo et al. 2015, Phillip et al. 2019).

In addition to public health concerns, container mosquitoes like the yellow fever mosquito and the Asian tiger mosquito are a major source of annoyance. These mosquitoes are adapted to living closely with humans and taking frequent blood meals from humans and their domestic animals. They are daytime biters and responsible for many complaints to mosquito control programs. However, because mosquito control programs cannot access all properties, community participation is essential in controlling container mosquitoes (Healy et al. 2014). The best way to reduce container mosquito populations is to remove 
habitats available for immature mosquito development. Because reducing container mosquitoes requires community participation, this publication outlines how to develop and host a community cleanup to dispose of potential container mosquito habitats.

\section{Planning the Container Mosquito Habitat Community Cleanup}

Identify the targeted area for cleanup. Vacant fields, abandoned lots, alleyways, and roadsides are susceptible to illegal dumping that creates eyesores, environmental hazards, and immature mosquito habitats. Keep in mind that permission to access the targeted property may be required. A walk-through and investigation of your potential site will be necessary to determine the type of waste that will be collected and how it will need to be disposed.

Waste disposal. Make an itemized list of potential supplies needed to safely collect container mosquito habitats at your selected site, such as heavy-duty garbage bags, gloves, trash grabbers, and high visibility safety vests. An example supply list is provided below. Purchase those items before your community cleanup event. Additionally, research how to legally dispose of the container mosquito habitats that you will be removing from your selected site. Waste disposal guidelines vary by county, and specific items, such as tires or building materials, must be disposed of correctly to prevent creating further environmental damage and to avoid potential fines. Waste management or community leaders may need to be contacted and can be valuable resources in planning a community cleanup event. Most counties in Florida have a recycling coordinator who can offer guidance, and up-to-date contact information can be found on most county waste management websites.

A special word about disposing of used tires. The Florida Department of Environmental Protection (FDEP) oversees the transportation, storage, processing, and disposal of used tires, and it is beneficial to understand FDEP and county used-tire regulations if planning to clean up a site containing used tires. For instance, it is illegal for anyone other than a waste tire collector registered with FDEP to transport more than 24 used tires at one time (FDEP 2015). The options available to residents for disposing of up to 24 tires can vary by county. For example, some counties offer free curbside collection service for a certain number of tires. Some counties allow residents to bring tires to a landfill for free on specified days or for a fee on other days. If you will be disposing of tires, you should determine in advance if a fee will be charged.
Advertising. Consider using multiple avenues to recruit potential volunteers and gain community support for your endeavor, such as local television and radio stations, newspapers, and social media. Create a flier that includes specific details about your cleanup event, including date, time, location, and contact information that can be easily shared. A "before" picture of the site you have chosen for cleanup may be a worthwhile addition to your flier. A large cleanup event may require fundraising or donations. Sharing your event flier with local businesses could encourage contributions.

Mobilize volunteers. After deciding on a community cleanup site, volunteers need to be organized for the event. It is beneficial to have the answers to the following questions:

- Do you have enough volunteers to get the work done?

- Will this event be open to just one organization, such as a Boy Scout troop or a religious group?

- Should you get other groups involved to have further reach or potentially more credibility when dealing with potential donors?

- During what stages of the event will volunteers be needed? Are volunteers needed for only the cleanup? Or will volunteers be needed to accompany you to the waste management site to help dispose of what was collected?

- What is the scale of the cleanup? Will it be so large that volunteers should be divided into separate groups to work on different days?

Determine how tasks will be assigned. If possible, decide in advance what task each person should be assigned to do. For example, a volunteer with physical limitations may be better suited for overseeing the registration process instead of lifting potentially heavy objects. Keep in mind that friends who signed up together may have more fun working together (Figure 6). Consider that a team-style approach may lead to increased productivity, and encourage groups to sign up together. Also, assign team leaders if necessary. A simple chain of command can provide organization for those in charge and structure for the participants looking for direction.

\section{During the Container Mosquito Habitat Community Cleanup}

Safety and liability. Before getting started, ensure that volunteers are made aware of any potential risks and how to prevent injuries through a safety orientation. If there is any treacherous terrain, inform participants of the location. 


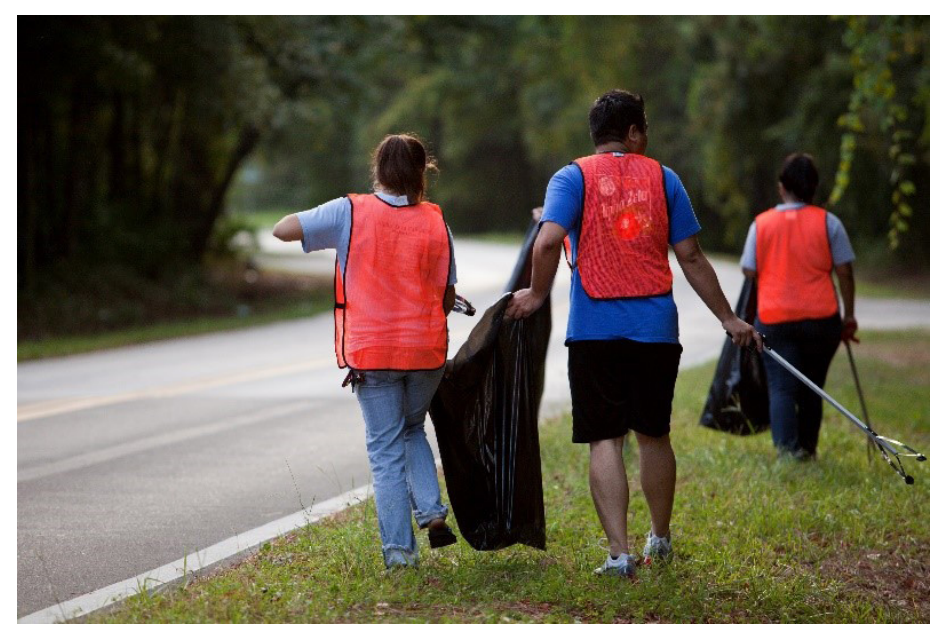

Figure 6. Friends picking up waste together at a community cleanup event. Image was taken prior to national guidelines of face coverings and social distancing

Credit: Tyler Jones, UF/IFAS

Warn volunteers about potential venomous arthropods and snakes that they might encounter while moving items like tires. They should also be told to exercise caution when picking up any materials that may have sharp edges. Have participants read and sign a liability release to make sure they understand all potential risks and protect your organization. An example of a liability release form can be found here: https://ordway-swisher.ufl.edu/docs/os-Release_of_liability.pdf.

Remember to pass out insect repellant, sunscreen, and proper protective equipment, such as gloves, to volunteers. Make sure participants have access to water and a first aid kit. This would also be a perfect opportunity to educate participants on why eliminating standing water and potential larval habitats is important public health work. If notified in advance, local mosquito control programs may even want to get involved. They may even be able to provide educational materials.

Atmosphere. Now that the volunteers have arrived and the planning is coming to fruition, get to know the volunteers. Thank them and instill a sense of ownership in their community effort. Take photos during the event to feature participants' contributions after receiving permission to take their photos.

\section{Post-Container Mosquito Habitat Community Cleanup}

After the event. Take an "after" picture of your site and compare it to the "before" picture to show what your group accomplished. Once you have met your objectives or your time frame is over, collected materials must be disposed of at the appropriate waste management and/or recycling center. Keep in mind that county waste management sites usually require those dropping off materials to unload their own vehicles.

\section{Concluding Comments}

The best way to reduce container mosquito populations is to eliminate potential immature mosquito habitats. By following the recommendations in this publication, you can successfully develop and host a cleanup event in your community. A simplified checklist for organizing an event as well as a potential list of supplies needed are provided below. Before the event, remember to advertise and visit the site where your cleanup will take place. Decide if you will need supplies beyond those listed below. Determine appropriate disposal methods for the waste that may be collected. During the event, make sure all participants complete liability release forms. Help keep your volunteers safe, hydrated, and comfortable. Recognize them for the public health impact of their work. Use before and after pictures of your cleanup site to highlight what your group accomplished.

Did you have a successful container mosquito habitat cleanup event or do you have suggestions for improving this document? Email eva.buckner@ufl.edu with the location, number of volunteers, and number of tires or other types of habitats collected, and/or with your suggestions.

\section{Container mosquito habitat community cleanup: Organizer's checklist}

\section{Before the Event}

— Identify target area for cleanup event.

— Take "before" pictures of the site.

- Identify any potential hazards at the chosen site.

— Research legal disposal methods.

- Create a plan for removing collected waste from site after the event.

- Make an itemized supply list (example provided below) and purchase supplies.

- Decide on your target volunteer audience and set a date and time. 
- Advertise your event.

- Determine how tasks will be divided and determine leaders for the day of the event.

- Make sure to create a Release of Liability form for the event.

\section{During the Event}

— Have everyone sign the Release of Liability form.

- Give orientation to volunteers that includes safety information and explanation of why their participation is impactful.

- Proceed with cleanup tasks.

- Take photos during the event to highlight work accomplished by volunteers. Make sure you have participants' permission to take their photos.

— Thank volunteers for their participation.

— Take "after" pictures of the site.

- Dispose of waste in an appropriate manner.

\section{Suggested Supplies List}

- Safety vests

— Trash grabbers

- Insect repellent

- Sunscreen

- Gloves

- Trash bags

- Release of Liability forms

- Water

- Snacks

- First aid kit

- Camera or cellphone for pictures

\section{References}

Arévalo, M. T., G. A. Kirchenbaum, M. C. Lanteri, S. L. Stramer, M. Ramgopal, and T. M. Ross. 2015. Dengue outbreak in Martin County, Florida in 2013. Journal of Human Virology and Retrovirology 2:00072. DOI: 10.15406/ jhvrv.2015.02.00072.

Bortel, W. V., F. Dorleans, J. Rosine, A. Blateau, D. Rousset, S. Matheus, I. Leparc-Goffart, O. Flusin, C. M. Prat, R. Césaire, F. Najioullah, V. Ardillon, E. Balleydier, L. Carvalho, A. Lemaître, H. Noël, V. Servas, C. Six, M. Zurbaran, L. Léon, A. Guinard, J. van den Kerkhof, M. Henry, E. Fanoy, M. Braks, J. Reimerink, C. Swaan, R. Georges, L. Brooks, J. Freedman, B. Sudre, and H. Zeller. 2014. Chikungunya outbreak in the Caribbean region, December 2013 to March 2014, and the significance for Europe. Eurosurveillance 19:20759. DOI: 10.2807/1560-7917.es2014.19.13.20759.

Campos, G. S., A. C. Bandeira, and S. I. Sardi. 2015. Zika Virus Outbreak, Bahia, Brazil. Emerging Infectious Diseases 21:1885-1886. DOI: 10.3201/eid2110.150847.

Florida Department of Environmental Protection (FDEP) Division of Waste Management. 2015. 2011-2014 Waste Tires in Florida, State of the State Report. https://floridadep. gov/waste/permitting-compliance-assistance/content/tirespublications. Accessed 14 July 2019.

Healy, K., G. Hamilton, T. Crepeau, S. Healy, I. Unlu, A. Farajollahi, and D. M. Fonseca. 2014. Integrating the public in mosquito management: Active education by community peers can lead to significant reduction in peridomestic container mosquito habitats. PLoS ONE 9: e108504. DOI: 10.1371/journal.pone.0108504.

Kendrick, K., D. Stanek, and C. Blackmore. 2014. Notes from the field: Transmission of chikungunya virus in the continental United States - Florida, 2014. MMWR Morbidity and Mortality Weekly Report 63:1137.

Parker, C., D. Ramirez, and C. R. Connelly. 2019. State-wide survey of Aedes aegypti and Aedes albopictus (Diptera: Culicidae) in Florida. Journal of Vector Ecology 44:210-215. DOI: 10.1111/jvec.12351.

Philip, C., C. G. Novick, and L. F. Novick. 2019 Local transmission of Zika virus in Miami-Dade County. Journal of Public Health Management and Practice 25:277-287. DOI: 10.1097/PHH.0000000000000990. 
Radke, E. G., C. J. Gregory, K. W. Kintziger, E. K. SauberSchatz, E. A. Hunsperger, G. R. Gallagher, J. M. Barber, B. J. Biggerstaff, D. R. Stanek, K. M. Tomashek, and C. G. M. Blackmore. 2012. Dengue outbreak in Key West, Florida, USA, 2009. Emerging Infectious Diseases 18:135-137. DOI: 10.3201/eid1801.110130.

Rey, J. R. 2014. Dengue in Florida (USA). Insects 5:991-1000. DOI: 10.3390/insects5040991.

Yee, D. A. 2008. Tires as habitats for mosquitoes: A review of studies within the Eastern United States. Journal of Medical Entomology 45:581-593. DOI: 10.1093/ jmedent/45.4.581. 